\title{
EFFICIENCY ANALYSIS OF USING A COMBINATION OF AIR AND GROUND HEAT PUMPS FOR HEATING AND VENTILATION
}

\author{
Bezrodny M.K., Oslovskyi S.A. \\ National Technical University of Ukraine "Igor Sikorsky Kyiv Polytechnic Institute”, Kyiv, Ukraine, \\ work.oslovskiy@gmail.com
}

\begin{abstract}
The article considers the energy efficiency of the combination of two most common heat sources for heat pumps, namely soil and ambient air. A feature of such a system is the connection of air and ground heat pumps in series with water. A computational model of the proposed system is developed, based on the system of equations for heat and material balances of the system. The result of the analysis was a system of equations, the analysis of which made it possible to study the two main characteristics of energy efficiency, namely, the relative heat load of the ground heat exchanger and the specific total costs of external work for the drive of the system, depending on the depth of utilization of the heat of ventilation emissions. It is shown that a positive effect from the use of a heating and ventilation system with two heat pumps, both in terms of energy and investments, can be achieved with the utilization depth of ventilation emissions corresponding to the condition of equality of the conversion factors for air and ground heat pumps.
\end{abstract}

Keywords: heat pump, ventilation emissions, soil heat, energy efficiency, specific work, atmospheric air, combination of heat sources.

\section{Introduction}

According to the statistics of the International Energy Agency (IEA), in 2019, residential and commercial buildings accounted for $49 \%$ of the total final consumption (TFC) of global electricity and $15 \%$ of the TFC of fossil fuels [1]. Heating, ventilation and air conditioning (HVAC) systems account for a significant share of total energy consumption in residential and public buildings [2]. Consequently, energy savings in HVAC systems play an important role in improving the overall energy savings of a building. Significant success in solving these problems has been achieved in European countries [3], in the USA [4], in Japan [5], in China [6] and in other regions of the world through the use of heat pump technologies with high energy efficiency in HVAC systems.

At the same time, a number of problems with the use of existing heat pump technologies are determined by the conditions of their application and require their solution. To provide year-round heat supply to buildings, air HP is the most popular type among others $[8,9]$. However, it cannot be used in areas with cold winters due to the risk of freezing of the evaporator. When air heaters are used in winter, low ambient temperatures cause a drop in the evaporation temperature, which leads to a catastrophic decrease in efficiency, a drop in condensation temperature or even a system shutdown [10]. In other cases, when air-towater heat transformers can operate in winter to heat a building, their COP (coefficient of performance) is usually much lower than that of ground-water heat transformers, due to the higher temperature of the heat source - the ground [7].

Therefore, it can be concluded that the use of atmospheric air as a lower source of heat in heat pump heating of buildings is ineffective in latitudes with cold winters [11]. The temperature level of the outside air does not allow achieving the required effect from the use of a heat pump. The authors [12-14] considered various combinations of low-grade heat sources with both air and ground heat pumps, their efficiency and productivity were shown. However, there was a problem of low productivity of a single HPU to provide heat supply for ventilation and air conditioning systems in public buildings with a large volume. For such purposes, it is necessary to choose a heat carrier with a higher temperature potential, but at the same time, it is also easily accessible. This source is the exhaust air from ventilation systems. It should be noted that the use of ventilation emissions as a source of heat has a number of advantages, namely: high and constant temperature potential, reliability, cyclicity of the heat recovery system (the heat spent on heating the supply air is reused) [15]. However, when using an air-to-water heat pump operating on ventilation emissions at 
facilities where the consumption of thermal energy by the heating system significantly exceeds that in the ventilation system, the capacity of such a HPU to provide both heating and ventilation may not be enough [16]. This problem can be solved with the help of cascade use of heat pumps with air and ground source of heat. The peculiarity of the proposed solution lies in the use of a series connection by water of condensers of air and ground HP. The use of such a solution at the design stage of the heating and ventilation system will allow balancing the advantages and disadvantages of the two most used types of HP and will create conditions for a more efficient use of heat pump technologies in general.

\section{Description of the scheme and problem statement}

A schematic diagram of the above-described solution for heat supply of heating and ventilation systems of a building using two series-connected heat pumps (air and ground) is shown in Fig. 1. The main specific characteristic of the presented scheme is the use of air and ground HP connected in series along the water circuit. Analyzing the scheme, you can see that the ventilation emissions with a temperature $t_{\text {in }}$ (temperature inside) are injected into the evaporator of the air HP, where it gives off heat to the freon, evaporating it and thereby cooling to the temperature $t_{\mathrm{ev}}$. Next, the coolant is heated in the condenser from the $t_{\mathrm{r}}$ (return water) to the $t_{\mathrm{g}}$ (intermediate). The coolant is heated to the required design temperature $t_{\mathrm{c}}$ by means of ground HP.

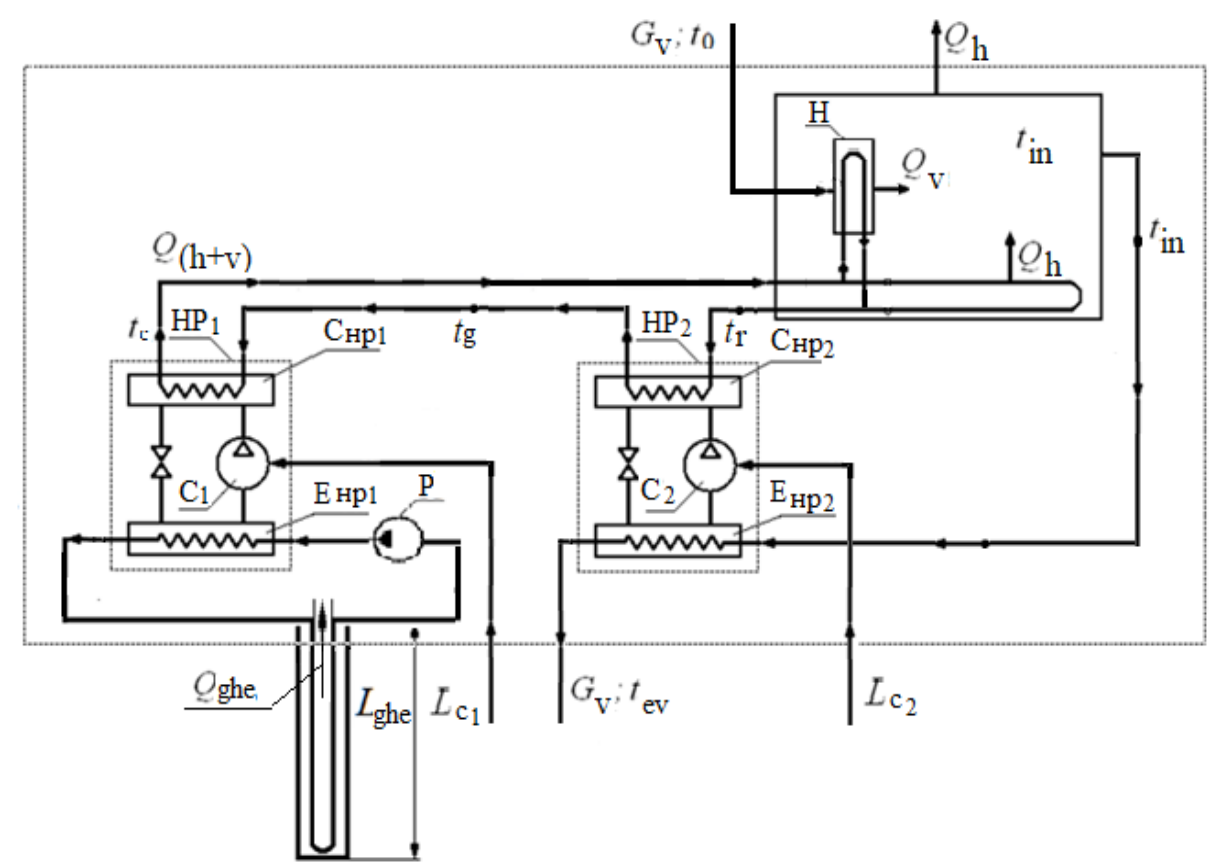

Fig.1. Schematic diagram of a cascade connection of air and ground heat pumps to provide heating and ventilation of the facility: $\mathrm{HP}_{1,2}$-ground and air heat pumps; $\mathrm{C}_{\mathrm{нр} 1,2}$ - condensers of ground and air heat pumps; $\mathrm{E}_{\mathrm{нр} 1}, \mathrm{E}_{\mathrm{нр} 2}$ - evaporators of ground and air heat pumps; $\mathrm{C}_{1}, \mathrm{C}_{2}-$ compressors of ground and air heat pumps; $\mathrm{H}$-heater of fresh air; $\mathrm{P}$ - pump of ground heat pump.

The main objective of the development of this combined solution is the pursuit of waste-free heat production, maximum energy efficiency of the system, as well as minimization of capital costs for the construction of the system. The qualitative and quantitative indicators of these values were determined based on thermodynamic analysis.

\section{Efficiency analysis of the considered system}

A feature of this scheme is the sequential use of two lower heat sources (heat of ventilation emissions and heat of the ground), which, together with the energy of the compressor drives, must be provided by the heating and ventilation system of the facility. The task is to optimize the use of each of these sources of increasing the system efficiency as a whole. At the same time, an increase in the efficiency of the system implies a decrease in both the energy costs for driving heat pumps and a decrease in the share of the heat load covered by the use of soil heat, which is associated with a decrease in capital costs for the construction 
of a ground heat exchanger. It is most convenient to change the proportion of use of individual heat sources by changing the depth of use of the heat of ventilation emissions, setting different levels of air temperature $t_{\mathrm{ev}}$ after the evaporator of the air HP. Then, assuming the given temperature $t_{\mathrm{ev}}$, the part of the total heat consumption for heating and ventilation can be determined from the heat balance equation of the entire circuit, which has the form

$$
G_{\mathrm{v}} C_{\mathrm{v}} t_{0}+Q_{\mathrm{ghe}}+L_{\mathrm{c} 1}+L_{\mathrm{c} 2}=Q_{\mathrm{h}}+G_{\mathrm{v}} C_{\mathrm{v}} t_{\mathrm{ev}} .
$$

Introducing into consideration (for the sake of convenience) the base air temperature $t_{\text {in }}$ inside the room, equation (1) can be written as

$$
G_{\mathrm{v}} C_{\mathrm{v}}\left(t_{\text {in }}-t_{\mathrm{ev}}\right)-G_{\mathrm{v}} C_{\mathrm{v}}\left(t_{\text {in }}-t_{0}\right)+Q_{\mathrm{ghe}}+L_{\mathrm{c} 1}+L_{\mathrm{c} 2}=Q_{\mathrm{h}}
$$

Taking into account the balance ratios for the quantities $L_{\mathrm{c} 1}, L_{\mathrm{c} 2}$ и $Q_{\mathrm{ghe}}$

$$
\begin{aligned}
& L_{\mathrm{c} 1}=\frac{Q_{\mathrm{EV} 1}}{\varphi_{1}-1} \\
& L_{\mathrm{c} 2}=\frac{Q_{\mathrm{EV} 2}}{\varphi_{2}-1} \\
& Q_{\mathrm{ghe}}=Q_{\mathrm{EV} 1},
\end{aligned}
$$

where $\varphi_{1}$ and $\varphi_{2}$ - coefficient of performance (COP) of air and ground HP, equation (2) takes form

$$
Q_{\mathrm{EV} 2} \frac{\varphi_{2}}{\varphi_{2}-1}+Q_{\text {ghe }} \frac{\varphi_{1}}{\varphi_{1}-1}=Q_{\mathrm{h}}+Q_{\mathrm{v}} .
$$

The sum of heat consumption for heating and ventilation is conveniently represented in the form

$$
Q_{\mathrm{h}}+Q_{\mathrm{v}}=Q_{\mathrm{v}}\left(1+\frac{1}{m}\right)=Q_{\mathrm{v}} \frac{m+1}{m},
$$

where $m=Q_{\mathrm{v}} / Q_{\mathrm{h}}$ - the ratio of the heat consumption for ventilation to the heat consumption for heating. Then, taking into account (7), equation (6) can be written in the form

$$
\frac{Q_{\mathrm{EV} 2}}{Q_{\mathrm{v}}} \frac{\varphi_{2}}{\varphi_{2}-1}\left(\frac{m}{m+1}\right)+\frac{Q_{\mathrm{ghe}}}{Q_{\mathrm{h}}+Q_{\mathrm{v}}} \frac{\varphi_{1}}{\varphi_{1}-1}=1,
$$

whence the expression for the part of heat of the ground heat exchanger in the total heat consumption for heating and ventilation follows

$$
\frac{Q_{\mathrm{ghe}}}{Q_{\mathrm{h}}+Q_{\mathrm{v}}}=\left[1-\frac{t_{\mathrm{in}}-t_{\mathrm{ev}}}{t_{\mathrm{in}}-t_{0}} \frac{\varphi_{2}}{\varphi_{2}-1} \frac{m}{m+1}\right] \frac{\varphi_{1}-1}{\varphi_{1}} .
$$

$\operatorname{COP} \varphi_{1}$ and $\varphi_{2}$ can be represented in the form of ratios:

$$
\begin{gathered}
\varphi_{1}=\eta_{\mathrm{HP}} \varphi_{1}^{\mathrm{i}}=\eta_{\mathrm{HP}} \frac{1}{1-\frac{273+t_{\mathrm{ev}}^{\mathrm{ex}}-\Delta t_{\mathrm{ev}}}{273+t_{\mathrm{c}}+\Delta t_{\mathrm{c}}}}, \\
\varphi_{2}=\eta_{\mathrm{HP}} \varphi_{2}^{\mathrm{i}}=\eta_{\mathrm{HP}} \frac{1}{1-\frac{273+t_{\mathrm{ev}}-\Delta t_{\mathrm{ev}}}{273+t_{\mathrm{g}}+\Delta t_{\mathrm{c}}}},
\end{gathered}
$$

where $\eta_{\text {НР }}$ - heat pump loss factor; $\varphi_{1}^{\mathrm{i}}$ и $\varphi_{2}^{\mathrm{i}}$ - theoretical COP of ground and air HР; $t_{\mathrm{c}}$ - outlet water temperature; $t_{\mathrm{g}}$ - intermediate water temperature; $t_{\mathrm{ev}}^{\mathrm{ex}}$ and $t_{\mathrm{ev}}$ - evaporator outlet water temperature, air and ground HP, respectively.

Water temperature between two HP condensers $t_{\mathrm{g}}$ can be determined from the heat balance of the ground HP

$$
Q_{\mathrm{ev}}+L_{\mathrm{c}}=Q_{\mathrm{c}} \text {. }
$$


Taking into account expressions (3), (5) and the expression for the heat flow in the condenser of the ground heat pump

$$
Q_{\mathrm{c}}=G_{\mathrm{w}} c_{\mathrm{w}}\left(t_{\mathrm{c}}-t_{\mathrm{g}}\right)
$$

equation (12) can be written as

$$
Q_{\text {ghe }} \frac{\varphi_{1}}{\varphi_{1}-1}=G_{\mathrm{w}} c_{\mathrm{w}}\left(t_{\mathrm{c}}-t_{\mathrm{g}}\right),
$$

where the water equivalent $G_{\mathrm{w}} c_{\mathrm{w}}$ can be determined from the heat balance of the upper circuit and has the form

$$
G_{\mathrm{w}} c_{\mathrm{w}}=\frac{Q_{\mathrm{v}}}{t_{\mathrm{c}}-t_{\mathrm{r}}} \frac{m+1}{m} .
$$

Taking into account equation (15), equation (14) takes the form

$$
\frac{Q_{\mathrm{ghe}}}{Q_{\mathrm{v}}} \frac{\varphi_{1}}{\varphi_{1}-1}=\frac{\left(t_{\mathrm{c}}-t_{\mathrm{g}}\right)}{\left(t_{\mathrm{c}}-t_{\mathrm{r}}\right)} \frac{m+1}{m} \text {. }
$$

Determining from (7) and (9) the ratio $Q_{\text {ghe }} / Q_{\mathrm{v}}$ and substituting it into (16), we obtain an equation for the intermediate water temperature between air and ground HP

$$
t_{\mathrm{g}}=t_{\mathrm{c}}-\left(t_{\mathrm{c}}-t_{\mathrm{r}}\right)\left[\frac{t_{\mathrm{in}}-t_{\mathrm{ev}}}{t_{\mathrm{in}}-t_{0}} \frac{\varphi_{2}}{\varphi_{2}-1} \frac{m}{m+1}\right]
$$

Along with equation (9) for determining the relative power of the ground heat exchanger, an important characteristic of the system efficiency is the specific total consumption of external energy for HP drives

$$
l_{\mathrm{h}+\mathrm{v}}=\frac{L_{\mathrm{c} 1}+L_{\mathrm{c} 2}}{Q_{\mathrm{h}}+Q_{\mathrm{v}}} .
$$

Taking into account the above relations (3) - (5), as well as (7) and (9), the equation for determining the specific total costs of external energy can be represented in the form

$$
l_{\mathrm{h}+\mathrm{v}}=\frac{1}{\varphi_{1}}-\frac{\left(t_{\text {in }}-t_{\mathrm{ev}}\right)}{\left(t_{\mathrm{in}}-t_{0}\right)} \frac{1}{\varphi_{2}-1} \frac{m}{m+1}\left(\frac{\varphi_{1}}{\varphi_{2}}-1\right) .
$$

\section{Discussion of results}

To implement the numerical solution of the compiled mathematical model of the system under consideration, the following initial data were taken. A low-temperature heat supply system with a temperature schedule of 40/30 was accepted for analysis, taking into account changes in the temperature of the coolant in the supply and return pipelines according to the recommendations [17]. The calculated temperature of the atmospheric air was taken at the level $t_{0}^{\mathrm{e}}=-20^{\circ} \mathrm{C}$, and the air temperature in the heat supply facility was $t_{\text {in }}=20^{\circ} \mathrm{C}$. The values of the characteristic temperatures of the coolant in the lower circuit of the ground HP were taken taking into account the measurement data in [18, 19], and the temperature difference in the evaporator, taking into account the maintenance of the optimal value in accordance with the analysis in [7]. The ratio of heat consumption for ventilation and heating was taken in the range $m=0.5 \ldots 4.0$ and covers working conditions from individual residential buildings to large shopping centers. The above mathematical model was solved numerically by preliminary determination of the intermediate water temperature $t_{\mathrm{g}}$ according to equation (17) taking into account equations (10), (11) by the method of successive approximations. At the first stage, the determination of the rational depth of use of each of the two lower sources of heat (ventilation emissions and soil) is carried out on the basis of minimizing the specific costs of external energy for the drive of the system by changing the depth of use of the heat of ventilation emissions, setting different levels of air temperature $t_{\mathrm{v}}$ after the evaporator of air heat pump. The calculation results are shown in Fig. 2 in the form of the dependence of the specific energy consumption on the air temperature after the evaporator of the air HP. It can be seen that for all parameters there is an optimal value of the air temperature $t_{\mathrm{v}}$, at which a minimum of total energy consumption is 
provided. This is determined by the different nature of the dependence of the COP of the ground and air HP on the temperature $t_{\mathrm{v}}$ and their different contribution to ensuring the total heat consumption.

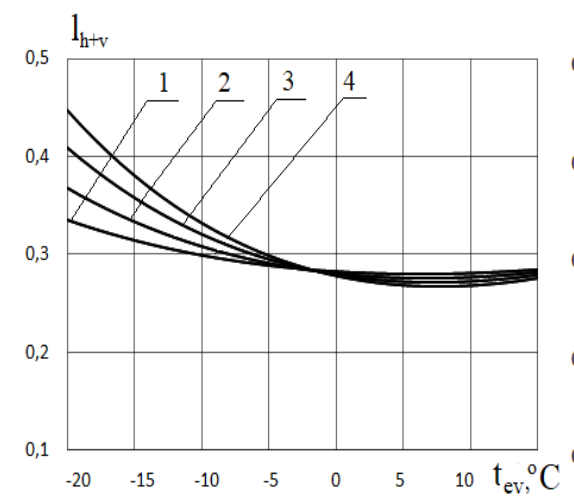

a)

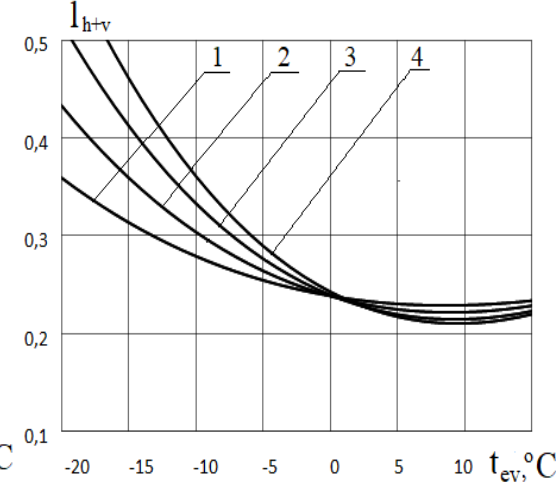

b)

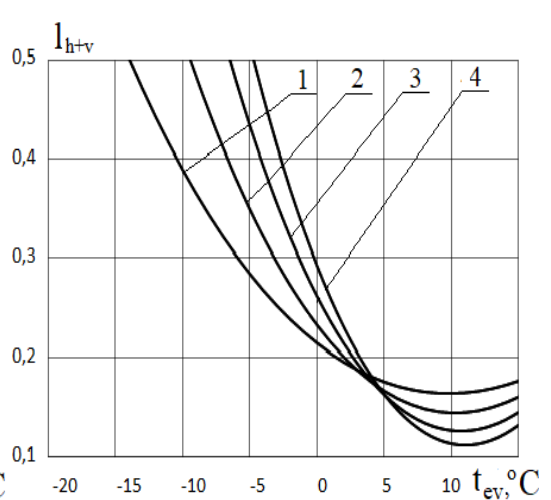

c)

Fig.2. Dependence of the specific consumption of external energy on the temperature at the outlet of the evaporator of the air HP: a-c - temperature $t_{0}=-20 ; 0 ; 15^{\circ} \mathrm{C}$ respectively; $1-4-m=0,5 ; 1 ; 2 ; 4$ respectively.

In fig. 3 shows the dependence of the detected optimal values of the air temperature $t_{\mathrm{v}}$ on the temperature of the atmospheric air and the parameter $m$. It can be seen that the optimal values of the temperature $t_{\mathrm{v}}$ increase with an increase in both the outside air temperature and the parameter $m$. At the same time, attention is drawn to the high level of temperatures of the air discharged into the atmosphere, that is, the low depth of use of the heat of the exhaust ventilation air [20]. As a result, the total heat load on the system is covered mainly by the operation of the ground heat exchanger, which is associated with an increase in the productivity of the ground heat exchanger and, as a consequence, the capital costs of its construction.

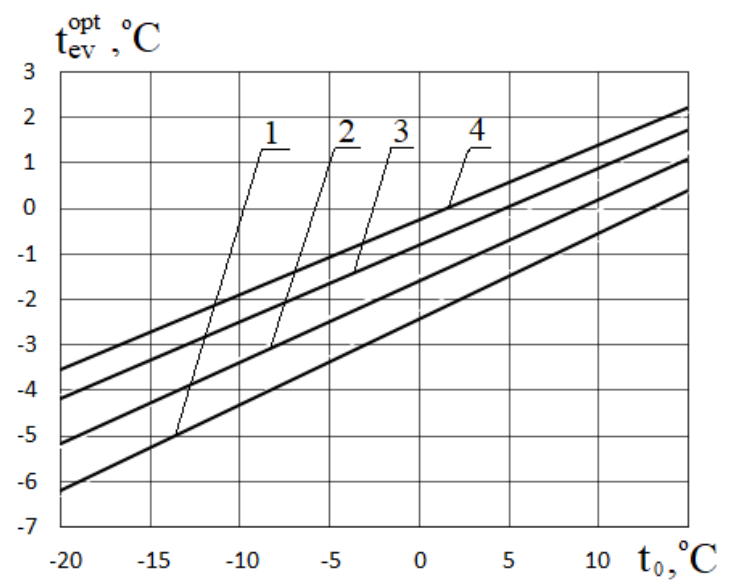

Fig.3. Dependence of the optimum air temperature at the outlet from the evaporator of the air HP on the outside air temperature: $1-4-m=0.5 ; 1 ; 2 ; 4$ respectively.

In this regard, it becomes expedient to consider other options (levels) of the heat load of the air HP or the depth of use of the heat of ventilation emissions [21]. Such an option can be the heat load of the air HP, selected from the condition of the same efficiency of operation of both heat pumps, that is, from the condition of equality of their COP. For this purpose, the corresponding COPs of two HP are shown in Fig. 4 depending on the temperature $t_{\mathrm{v}}$ at different values of the parameter $m$ and the outside air temperature. As seen from Fig. 4, the points of intersection of individual curves for the air HP and the dashed line for the ground HP correspond to different values of the air temperature at the outlet from the evaporator of the air HP, which satisfies the condition of equality of COP for both HP [22]. The dependence of these temperatures on the outside air temperature and parameter $m$ is shown in Fig. 5. The data in Fig. 5 indicate that the level of air temperatures at the outlet of the evaporator of the air HP under this condition is significantly lower than in Fig. 3 under the previously considered condition of the minimum total external work. 


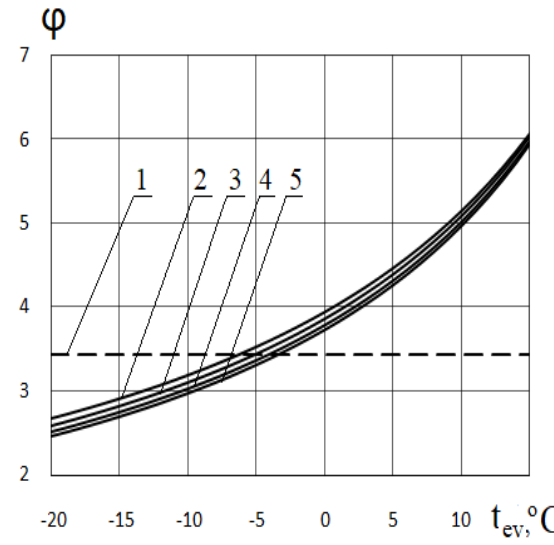

a)

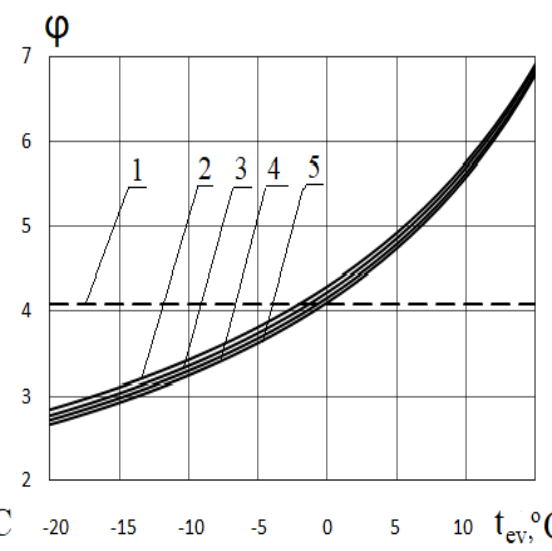

b)

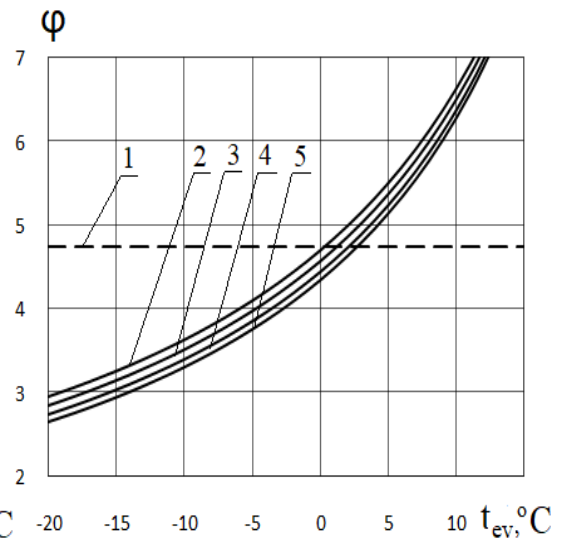

c)

Fig. 4. Dependence of the transformation ratio on the air temperature at the outlet of the evaporator of the air HP: $\mathrm{a}-\mathrm{c}-t_{0}=-20 ; 0 ; 15^{\circ} \mathrm{C}$ respectively; $1-\varphi_{1} ; 2-5-\varphi_{2}$ at $m=0.5 ; 1 ; 2 ; 4$ respectively.

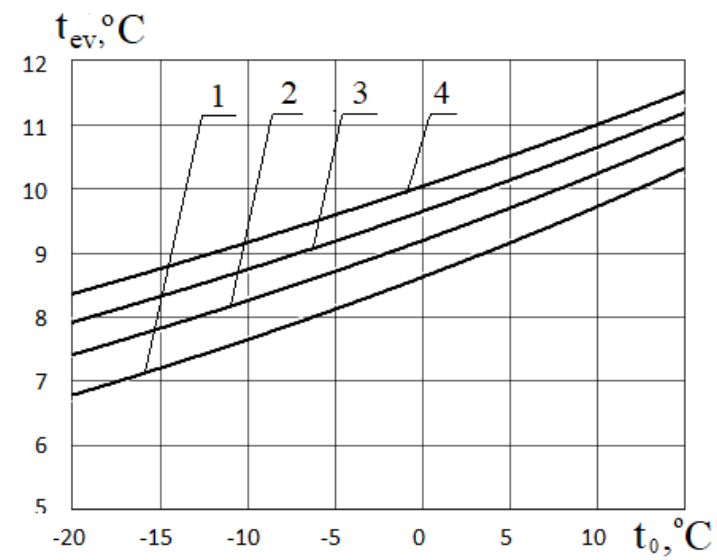

Fig. 5. Dependence of the air temperature at the outlet from the evaporator of the air HP on the outside temperature (COP equality condition): $1-4-m=0.5 ; 1 ; 2 ; 4$.

This indicates a greater load of the air HP and a lower thermal load of the ground HP, and, consequently, the lower required performance of the ground heat exchanger and the corresponding capital costs for its installation. Fig. 6 shows the dependence of the relative heat load of the ground heat exchanger on the outside air temperature and parameter $m$ under three comparison conditions (minimum external work, equal COP and complete heat recovery from the exhaust ventilation air).

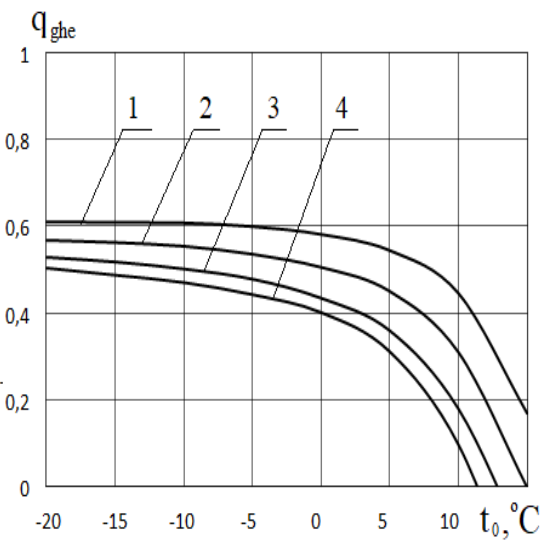

a)

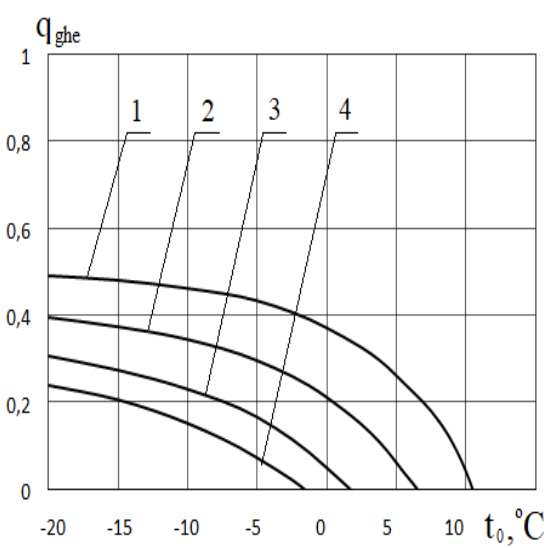

b)

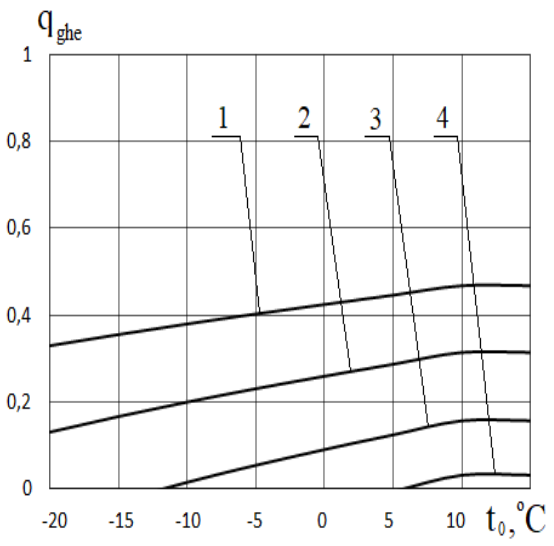

c)

Fig. 6. Dependence of load part of the ground heat exchanger in the total heat flow for heating and ventilation on the outside air temperature: a) condition for minimum unit energy consumption; b) COP equality condition;

c) $t_{\mathrm{ev}}=t_{0}$ condition, where $1-4-m=0.5 ; 1 ; 2 ; 4$. 
It can be seen that a relatively small decrease in temperature $t_{\mathrm{v}}$ to the level at which the equality of COP is observed (Fig. 6, b), significantly reduces the relative power of the ground heat exchanger. A further decrease in the temperature $t_{\mathrm{v}}$ to the outside air temperature (Fig. 6, c) leads to a qualitative change in the nature of the dependences, but does not cause particularly sharp quantitative changes in the value of $q_{\text {ghe }}$.

The dependence of the second important characteristic of the heat pump system - the specific consumption of external energy for the drive of the system - is shown in Fig. 7. It can be seen that the achievement of the COP equality condition (Fig. 7, b) has almost no effect on the amount of external work on the system drive, which does not depend on the ratio of heat consumption for ventilation and heating.

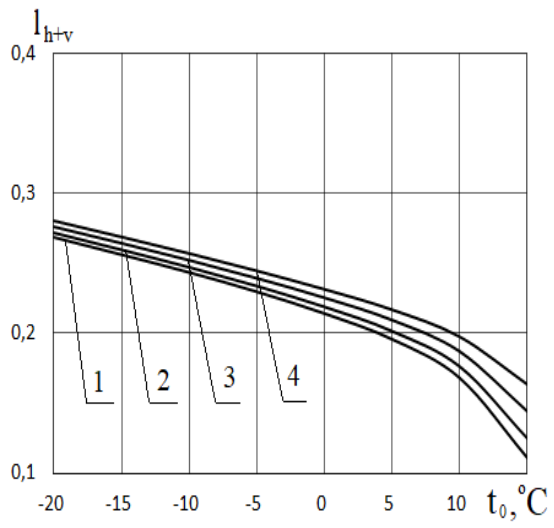

a)

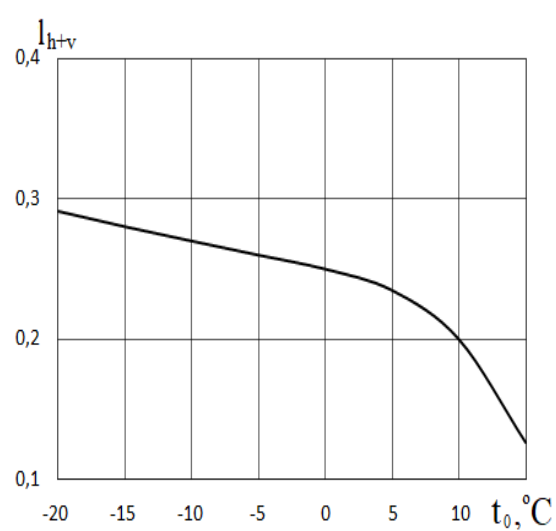

b)

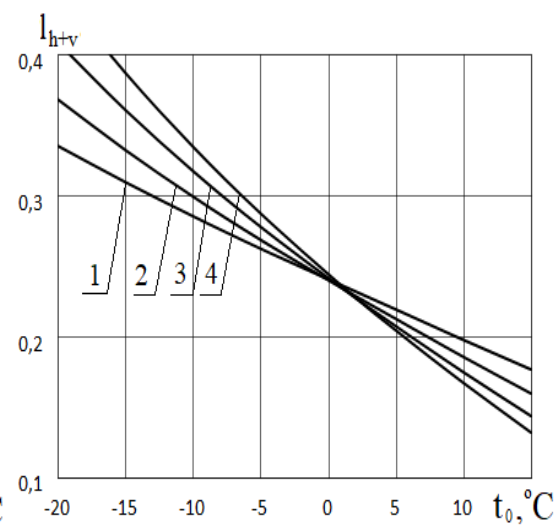

c)

Fig.7. Dependence of the specific consumption of external energy for the system on the outside temperature: a) condition for minimum unit energy consumption; b) COP equality condition;

$$
\text { c) } t_{\mathrm{ev}}=t_{0} \text { condition, for } 1-4 m=0,5 ; 1 ; 2 ; 4 \text {. }
$$

At the same time, a further decrease in the temperature $t_{\mathrm{v}}$ to the level $\mathrm{t}_{0}$ leads to a sharp increase in the specific work in the region of low outdoor temperatures. As a result, it can be concluded that the utilization of the heat of ventilation emissions in the considered heat pump system may be advisable when the air temperature after the evaporator of the air HP is reduced only to a level corresponding to the condition of equality of the COP of the air and ground heat pumps.

\section{Conclusions}

1. The use of a combined heat pump system for heating and ventilation of large facilities using air and ground heat pumps with its rational design can give a positive effect both in terms of energy and investment.

2. Rational design of a heating and ventilation system with two heat pumps can be carried out on the basis of a joint analysis of two most important characteristics of such a system, namely, the relative heat load of the ground heat exchanger and the specific total costs of external work on the system drive, depending on the depth of use of the heat of the ventilation emissions.

The analysis showed that a positive both energy and investment effect can be achieved at the depth of utilization of ventilation emissions, corresponding to the condition of COP equality of air and ground heat pumps.

\section{REFERENCES}

1 IEA, Renewable Energy Policies in a Time of Transition. International Energy Agency. 2020. Available at: https://webstore.iea.org/download/direct/426.

2 Katsura T. Development of optimum design method for the heat recovery ground source heat pump system. Proceeding of the $12^{\text {th }}$ IEA heat pump conference 2017. Rotterdam, 2017, No. 17, pp. $4-8$.

3 Ürge-Vorsatz D., Cabeza L., Serrano S., Barreneche C., Petrichenko K. Heating and cooling energy trends and drivers in buildings. Renewable and Sustainable Energy Reviews, 2015, No. 41, pp. 31-52.

4 Willem H., Lin Y., Lekov A. Review of energy efficiency and system performance of residential heat pump water heaters. Energy and Buildings, 2017, No. 143, pp. 191-201.

5 IEA, World Energy Outlook. International Energy Agency, 2019. Available at: www.iea.org/reports /worldenergy-outlook-2019. 
6 Chang J., Liu H., Wang C., Liu M. The applications and economic analysis of Ground Source Heat Pump (GSHP) in certain national games sports centre. Procedia Engineering, 2017, No. 70, pp. 12-36.

7 Bezrodny M. K., Pritula N.O. Thermodynamic and energy efficiency of heat pump heat supply circuits: monography, Kyiv, Polytechnica, 2016, 272 p.

8 Menberg K., Heo Y., Choi W., et al. xergy analysis of a hybrid ground-source heat pump system. Applied Thermal Engineering, 2017, No. 46, pp. 949-958.

9 Christodoulides P., Aresti L., Florides G. Air-conditioning of a typical house in moderate climates with ground source heat pumps and cost comparison with air source heat pumps. Applied Thermal Engineering, 2019 , No. 158, pp. 77-83.

10 Wang Z., Wang F., Liu J., et al. Field test and numerical investigation on the heat transfer characteristics and optimal design of the heat exchangers of a deep borehole ground source heat pump system. Energy Conversion and Management, 2017, No. 153, pp. 15-34.

11 Sarbu I., Sebarchievici C. General review of ground-source heat pump systems for heating and cooling of buildings. Energy and Buildings, 2014, No. 54, pp. 27 - 51

12 Bezrodny M.K., Prytula N.O., Oslovskyi S.A. Thermodynamic efficiency of the heat pump heating scheme using ground and waste water heat. Research Bulletin of the National Technical University of Ukraine "Kyiv Polytechnic Institute", 2018, No. 1, pp. 7-15.

13 Bezrodny M.K., Prytula N.O., Oslovskyi S.A. Analysis of the combined heat pump heating scheme using heat of atmospheric air and sewage water. Energy technology and resource conservation, 2018, No. 5, pp. 12-20.

14 Bezrodny M.K., Oslovskyi S.A. Energy efficiency of the heat pump recuperative heating and ventilation system using heat of ground and ventilation emissions. Power engineering: economics, technique, ecology, 2018, No. 3, pp. 95-103.

15 lshehri F., Beck S., Ingham D., et al. Techno-economic analysis of ground and air source heat pumps in hot dry climates. Journal of Building Engineering, 2019, No. 26, pp. 144 - 151.

16 Puhovy I., Postolenko A., Radchuk U. Analysis of heat supply schemes with two heat pumps and the use of ventilation emissions and air heated by the heat of water crystallization. Renewable Energy, 2014, No. 4, pp. 75-80.

17 Slastin A. Temperature dependence. 2020. Available at: www.ktto.com.ua/calculation/temperaturnyy_grafik [in Russian]

18 Kostikov A. O. Kharlampidi D. K. Influence of the thermal state of the soil on the efficiency of a heat pump installation with a ground heat exchanger. Power engineering: economics, technique, ecology, 2009, No. 1, pp. 32-40.

19 Basok B. I., Avramenko A.A., Ryzhkov S.S., Lunina A.A. The dynamics of heat transfer of liquid in a single rectilinear soil pipe element (heat exchanger). Industrial heat engineering, 2009, No. 1, pp. 62-67.

20 Qu M., Li T., Deng S., Fan Y, Li Z. Improving defrosting performance of cascade air source heat pump using thermal energy storage based reverse cycle defrosting method. Applied Thermal Engineering, 2017, No. 36, pp. 67-74.

21 Zeng C., Liu S., Shukla A. A review on the air-to-air heat and mass exchanger technologies for building applications. Renewable and Sustainable Energy Reviews, 2017, No. 75, pp. 137-144.

22 Bezrodny M.K., Misiura T.O. The heat pump system for ventilation and air conditioning inside the production area with an excessive internal moisture generation. Eurasian phys. tech. j., 2020, Vol. 17, No. 2(34), pp. 78 -86 . 